Revista Qualidade Emergente, 2016, v7 n.1: 1-16

\title{
ENDOMARKETING EM UMA ORGANIZAÇÃO DE RECICLAGEM, MÉTODO PARA UMA BOA IMPLANTAÇÃO
}

\section{ENDOMARKETING IN A RECYCLING ORGANIZATION, A GOOD METHOD FOR DEPLOYMENT}

Nilton Cesar Pasquini

\section{Resumo}

Trata-se de uma investigação exploratória do tipo estudo de caso. Tem como objetivo criar nos colaboradores orgulho de atuar na organização, diminuir o turnover. Criou um grupo formado por motorista, supervisor, analista de $\mathrm{RH}$, operadores de produção. Formulou um plano de ação, usou 5W2H e PDCA. Fez uso dos 4Ss sendo, análise, adaptação, ativação e avaliação. Utilizou algumas ferramentas adaptadas de Brun (1998) como vídeos - apresentação dos produtos e benefícios da empresa, com objetivo de colocar os colaboradores em contato direto com a realidade; manuais técnicos e de integração; palestras internas; grife interna distribuiu bonés, bolsas, mochilas, canetas, réguas, cadernos e canecas. $O$ endomarketing mudou a "cara" da empresa, aumentou a produção em $17 \%$ sem horas adicionais. Atingiu rapidamente 0 marketing externo, se tornando benchmarking na região de Americana SP, pois os colaboradores se tornaram multiplicadores da boa imagem.

Palavras-chave: endomarketing, gestão de pessoas, cliente interno, pesquisas de clima

\section{Abstract}

This is an explotarory invstigation of the case study. If aims creating pride in employees to act in the organization, reduce turover. Created a group of driver, supervisor, $\mathrm{RH}$ analyst, production operators. Formulated a plan of action, and used $5 \mathrm{~W} 2 \mathrm{H}$, DCA. 4Ss being made use of, analusis, adaptation, activation and evaluation. We used use some tools adapted Brun (1998) as videos - presentation of products and company benefits, with the goal of placing employees in direct contact with reality; technical manuals and integration, internal lectures, inner designer distributed hats, bags, backpacks, pens, rulers, notebook and mugs. The 
endomarketing changed the "face" of the company increased production by $17 \%$ without additional hours. Quickly reached the external marketing, becoming benchamarking in the region of Americana SP because employees become multipliers of good image.

Key-words: Internal marketing, people management, internal customer, climate research

\section{INTRODUÇÃO}

As organizações dependem das pessoas para proporcionar-Ihes o necessário planejamento e organização, e para fazê-las operar e funcionar. Não há organização sem pessoas. Toda organização é constituída de pessoas e depende delas para seu sucesso e continuidade. O estudo das pessoas constitui a unidade básica das organizações. Há que se considerar as pessoas sob duas vertentes: as pessoas como pessoas (dotadas de características próprias de personalidade e de individualidade, aspirações, valores, atitudes, motivações e objetivos individuais) e as pessoas como recursos (dotadas de habilidades, capacidades, destrezas e conhecimentos necessários para a tarefa organizacional) (CHIAVENATO, 1996).

Para Chiavenato (2008), a qualidade de vida é um complexo que envolve uma constelação de fatores, como: satisfação com o trabalho executado; possibilidades de futuro na organização; reconhecimento; salário percebido; liberdade; benefícios. Brum (2000) define marketing interno como dar ao funcionário educação, carinho e atenção, tornando-o bem preparado e bem informado para que possa tornar-se também uma pessoa criativa e feliz, capaz de surpreender, encantar e entusiasmar o cliente.

Para Kotler (1994, p. 37) marketing interno é a tarefa de contratações acertadas, treinamento e motivação de funcionários hábeis que desejam atender bem os clientes. Ele se refere à diferença entre o marketing interno e o marketing externo. Para o autor, o marketing interno deve preceder o externo.

Os principais objetivos do endomarketing são: i) Manutenção de um ambiente de trabalho, que proporcione motivação, valorização e reconhecimento das pessoas; ii) Aumento dos índices de produtividade e qualidade com a diminuição dos custos; iii) Criação de canais de comunicação entre todos, independente do nível hierárquico, para a eliminação de conflitos interpessoais e também para trocas de experiências, gerando assim uma melhoria nos relacionamentos (KOTLER, 1993, p.417). 


\section{ENDOMARKETING}

Endomarketing consiste em realizar ações de marketing voltadas para o público interno da empresa, com o objetivo de atrair e reter esses funcionários. Uma vez satisfeitos com a empresa, eles acabam produzindo mais e melhor e, como conseqüência, a empresa consegue obter resultados muito mais eficientes, entre os quais maior fidelização de seus clientes externos (BEKING, 2004).

O endomarketing está diretamente relacionado e alicerçado na base da cultura organizacional, cujo comprometimento dos seus funcionários com 0 desenvolvimento adequado das suas diversas tecnologias é condição primordial para o sucesso coletivo (CERQUEIRA, 2002).

Conforme a explicação de González (2000, p.12) com a aplicação do Marketing interno, os resultados econômicos tornam-se melhores, o que acontece porque se forma uma massa compacta de organização e de relações humanas dentro da companhia... assim, o objetivo principal do endomarketing é adotar na empresa os mecanismos necessários para desencadear um bom trabalho.... A motivação humana é um desafio enorme com o qual se deparam empreendedores, consultores, gerentes e outros líderes. Cada pessoa tem sua própria matriz motivacional e fazê-la mover-se é um passo de mágica a ser dado. Pois bem, o objetivo do endomarketing é o de propiciar um ambiente interno nas organizações que seja favorável ao surgimento desses momentos mágicos, através da oportunidade de tarefas estimulantes, ambiente motivador de trabalho, comunicação aberta e integral sobre o produto/serviço, as pessoas e sobre a empresa.

Brum (2005) acrescenta conceituando o endomarketing como forma de motivar os colaboradores por meio de programas internos. Para a autora, o melhor caminho para a motivação é a capacidade que algumas organizações têm de passar aos seus funcionários mensagens inspiradoras e coerentes, que os ajudem a adotar uma atitude positiva em relação a empresa em que trabalham.

O endomarketing hoje pode ser entendido como um processo estruturado, alinhado ao planejamento estratégico empresarial, visando melhoria da comunicação, buscando a relação com ganhos de produtividade nas organizações. Para que isso aconteça, são necessários conhecimentos de: indicadores de desempenho de Recursos Humanos, Clima Organizacional, indicadores de produtividade e apoio da alta gerência, principalmente (DIAS, 2008, p. 24). 
Existem duas linhas de ação para colocar os programas de endomarketing em prática segundo Bekin (1995). A primeira é a linha de ação de atitude, que visam dar ao funcionário consciência da importância estratégica de um serviço orientado para atender o cliente e a segunda é a linha de ação de comunicação, que contempla o sistema de informações capaz de dar subsídios para que todos possam cumprir suas tarefas com eficiência.

Dias (2008) cita que existe um modelo básico para implementação do processo de endomarketing, que pode ser adotado por qualquer organização, pois ele é perfeitamente ajustável. No entanto, para ele, mais importante que implantar ações de endomarketing é levar o programa realmente a sério, pois, uma vez que foi iniciado, deve ter continuidade, evitando a perda de credibilidade dos funcionários e desperdício de investimentos. E como é um processo que leva tempo para ser realizado, precisa ser sempre monitorado.

\section{CLIENTE INTERNO}

Cliente interno, na forma como se apresenta, é um eufemismo criado como panacéia para represar insatisfações do corpo funcional. Nas circunstâncias em que vem sendo adotado, assemelha-se ao descaramento de dizer que "por trás de um grande homem há sempre uma grande mulher", situação em que a mulher estará sempre próxima, mas nunca ao lado do "grande homem". O cliente interno, da mesma forma, é apresentado como o primeiro cliente de uma organização, só que nunca tem razão. Sua colaboração é sempre bem aceita, desde que as coisas se realizem exatamente como deseja e determina a administração superior, sem atender os reclamos e proposições de seus funcionários (INKOTTE, 2000).

\section{OBJETIVO}

Esta pesquisa trata-se de uma investigação exploratória do tipo estudo de caso. A pesquisa exploratória tem como objetivo proporcionar maior familiaridade com o problema, com vistas a torná-lo mais explícito ou a construir hipóteses. Podese dizer que essas pesquisas têm como objetivo principal o aprimoramento de idéias ou a descoberta de intuições. Já o estudo de caso: consiste no estudo aprofundo e exaustivo de um ou de poucos objetos, de maneira que permita seu amplo e detalhado conhecimento, havendo simplicidade nos procedimentos da pesquisa (GIL, 2007, p. 54). Criar nos colaboradores orgulho de atuar na organização, diminuir o turover. 


\section{METODOLOGIA}

Criou um grupo escolhido pela diretoria e supervisores, composto por 1 motorista, 1 supervisor, 1 analista de $\mathrm{RH}, 3$ operadores de produção. Formulou um plano de ação, onde fez uso da ferramenta 5W2H e PDCA, que segundo Oliveira (1996) $5 \mathrm{~W} 2 \mathrm{H}$ é uma das ferramentas da qualidade e serve como referência às decisões, permitindo que seja feito o acompanhamento do desenvolvimento do trabalho, Andrade (2003) considera o PDCA um modelo de gestão porque oferece, para os gestores, condições de conduzirem a empresa para onde desejam, evitando, dessa forma, que eles sejam guiados pelas crises e pelos problemas, porque neste caso, os gestores seriam meros apagadores de incêndios ocasionados pelas dificuldades cujas causas são desconhecidas.

Segundo Richers (2000), o sistema de 4As procura atender a necessidade de entrosamento entre as áreas, ao conceber o Marketing como um conjunto de tarefas ou funções que precisam ser coordenadas para que se possa realizar as tarefas operacionais de maneira sequencial e a custos controláveis.

Fez uso de 4 etapas de acordo com Marins et al., (2010).

Etapa 1 (Análise): nesta etapa é feita uma análise interna da empresa com os funcionários, gestores, etc. Analisando principalmente o clima organizacional, incluindo relacionamento, comunicação, valorização, oportunidades, entre outros aspectos. A análise e interpretação dos resultados poderão fornecer informações importantes para melhoria da produtividade da empresa.

Etapa 2 (Adaptação): serão elaboradas estratégias para uma possível mudança no comportamento organizacional da empresa, com a finalidade de um melhor clima organizacional e claro, um melhor rendimento produtivo para a empresa;

Etapa 3 (Ativação): nesta etapa é fundamental ter um diagnóstico, só a partir de uma avaliação cuidadosa e sistemática do ambiente interno da empresa o programa de Endomarketing poderá ter êxito;

Etapa 4 (Avaliação): esta etapa consiste em avaliar todo procedimento feito no ciclo da implementação da atividade na empresa, avaliando possíveis resultados, possíveis problemas ocorridos, sugestões previstas, entre outros aspectos.

Utilizou algumas ferramentas adaptadas de Brun (1998) como vídeos apresentação dos produtos e benefícios da empresa, com objetivo de colocar os colaboradores em contato direto com a realidade; manuais técnicos e de integração; 
os vídeos de integração contribuem para a divulgação em geral, ou, para reforçar algum aspecto cultural da organização; palestras internas; grife interna - distribuiu bonés, bolsas, mochilas, canetas, réguas, cadernos e canecas.

Carvalho (2010) afirma que o comando de endomarketing deve ser gerido por profissionais de marketing, que possuem perícia para encarar os diversos públicos, inclusive, o interno. Mas este projeto foi liderado por um Black belt.

\section{RESULTADOS}

Etapa 1 (Análise): As organizações representam um dos cenários em que as relações interpessoais acontecem. Estas relações sejam no nível pessoal ou profissional, constituem mecanismos de construção e sustentação do clima da organização que, por sua vez, orienta tanto o comportamento como o desempenho dos atores que nela participam. Assim, pode se afirmar que o clima é um elemento de fundamental importância na compreensão do comportamento e efetividade da organização (Puente-Palacios, Freitas; 2006).

Tentou-se produzir melhorias imediatas dentro das limitações orçamentárias e de pessoal que tínhamos. Com um melhor e mais imaginativo uso dos recursos existentes, conseguiu-se alguns resultados que serviram para motivar e mobilizar a equipe. No decorrer desta gratificante experiência, percebeu-se que é fundamental educar dando o exemplo, mediante real comprometimento com as ações do coletivo, ganhando assim credibilidade, e também ressaltar, constantemente, a importância da contribuição dos funcionários. Desta maneira, começou um processo de melhoria contínua (VANTI, 1999). Assim os gestores e diretores dedicaram um tempo para visitar a área operacional e conversar com colaboradores.

Constatou-se que as fontes de esgotamento físico e mental mais relatadas no ambiente são o excesso de atividades, a falta de planejamento, excesso de responsabilidade sem suficiente preparo, clareza nos objetivos do cargo, mudanças no trabalho, sobrecarga de trabalho, rapidez em realizar a tarefa, excessivo número de horas de trabalho, falta de participação na tomada de decisões, de responsabilidade, apoio da liderança e as relações pessoais.

Os colaboradores são compostos de $57 \%$ do sexo masculino e $43 \%$ do sexo feminino, onde exerce função desde motorista de treminhão à separador de resíduos, um total de 102 .

O horário estipulado é das 7:30 horas às 17 horas com folga no sábado e 
domingo, mas no ano de 2011 raras finais de semana os colaboradores não trabalharam, e sempre são avisados na véspera do dia.

Os trabalhadores são determinados pela supervisão e $\mathrm{RH}$ como "empregados", os atuantes na área administrativa não possuíam nível superior, apenas o $3^{\circ}$ colegial completo, na área operacional $12 \%$ possuíam o $3^{\circ}$ colegial, $58 \%$ a $8^{a}, 15 \%$ a $5^{\text {a }}$ série e $11 \%$ a $4^{\text {a }}$ série. Para empresa o termo colaborador e cliente interno não existem, a direção não desconhecia o termo. Acreditavam que os funcionários desempenhavam a função apenas para fazer a empresa funcionar, uma vez que recebem o salário tem a obrigação de atuar e falar bem da organização.

A empresa tem dificuldade em sanar suas vagas e em segurar seus colaboradores. Em novembro de 2011 ela oferecia $R \$ 100,00$ para o colaborador que indicasse alguém e desde que ficasse na empresa por 3 meses.

Constatou que $51 \%$ era fumante, 8 colaboradores tinham problema com álcool e 3 com drogas. O turnover médio da empresa em 2011 foi de $6 \%$ ao mês e índice de absenteísmo (la) de 0,9\% que corresponde a quase 150 horas perdida no mês.

A gestão de pessoas é formada inteiramente pela relação entre indivíduo e organização, esta integração já percebida há anos, visto que as pessoas passam boa parte de sua vida desempenhando alguma função em uma organização. Esta relação vem evoluindo, as organizações dependem das pessoas para alcançar seus objetivos e cumprir suas metas. Já as pessoas, buscam em uma organização formas para alcançar seus objetivos pessoais (CHIAVENATO, 2004). Porém na organização estudada esta relação estava quebrada, os colaboradores exerciam o que apenas os mandavam.

Foi realizado uma auditoria e entrevistado alguns colaboradores e fornecido uma pontuação para cada pergunta, 0 ruim, 1 regular e 2 bom. Através desta pontuação gerou a pontuação final, sendo 0 ruim (nenhum item atende ao padrão), 1 regular (poucos itens atendem ao padrão), 2 bom (muitos itens atende ao padrão) e 3 excelente (todos os itens atendem ao padrão). O comitê apresentou, para todos os envolvidos, os conceitos do endomarketing, os benefícios de sua prática (PASQUINI, 2012).

A empresa registrou em 2009, 2010 e 2011; 12, 9 e 15 acidentes com afastamento respectivamente, 23, 12 e 26 acidentes sem afastamento. Ao questionar os colaboradores se indicaria a empresa para algum amigo ou parente, $12(11,76 \%)$ 
responderam que sim, 90 (88,24\%) responderam que não. Note no gráfico 1 a insatisfação dos colaboradores antes da implantação do endomarketing, apenas o item relação com os colegas obteve nota 4, os demais foram inferior.

Os colaboradores sentiam vergonha da atividade que desempenhavam na organização, não sentiam ser profissionais e valorizados. Alguns saiam da empresa para ganhar até $10 \%$ a menos. Os funcionários da empresa eram os principais divulgadores negativos da empresa. Segundo Medeiros e Macêdo (2007) a precariedade refere-se ao trabalho mal remunerado, pouco reconhecido, que provoca um sentimento de inutilidade o trabalhador. Refere-se ainda à instabilidade do emprego, à ameaça do desemprego, à restrição aos direitos sociais e à falta de perspectivas de crescimento profissional, manifestada tanto em relação ao setor informal, quanto em relação à classe trabalhadora em geral.

Etapa 2 (Adaptação): Foi criado Padrão Operacional de Processo (POP) que informa quais atividades devem ser feitas e como, através das perguntas: $O$ que fazer? Quando fazer? Como Fazer? Por que fazer? Foi estabelecido quem é responsável pelo quê, pois a responsabilidade de todas tornasse responsabilidade de ninguém. Uma responsabilidade mais abrangente ou coletiva poderá ser aceitável quando o programa conseguir uma mudança cultural dos colaboradores (PASQUINI, 2012).

O equipamento de proteção (EPI) tinha seu uso banalizado por falta de conhecimento dos colaboradores, a empresa respeitava a legislação, mas não exigia com afinco seu uso, alguns modelos de equipamentos como luva, macacão e protetor auricular prejudicava a realização das atividades, assim preferiam não utilizá-los. Foi realizada uma reunião com fornecedor e trocou modelo de botina, luva, protetor auricular e capacete. Sendo assim, adaptação aos EPIs foi mais fácil. Segundo Costa e Costa (2004) o EPI é qualquer equipamento destinado ao uso individual do trabalhador com o objetivo de protegê-lo de um determinado agente de risco visando garantir a segurança e a saúde no trabalho. Qualquer complemento ou acessório destinado a tal fim também é considerado equipamento.

Benite (2004) diz que uma das ações efetivas para a segurança no trabalho são as reuniões de segurança nos locais de trabalho porque estas são mecanismos eficazes para a conscientização, visto que possuem dois grandes propósitos: educar e persuadir. 
Em 2012, houve 24 encontros entre treinamentos e palestras, abrangendo educação de filhos, relacionamento familiar, sexo e drogas, economia familiar, exame de Papanicolau e próstata, depressão, álcool e cigarro, motivação. Segundo Marras (2002) [...] treinamento é um processo de assimilação cultural em curto prazo, que objetiva repassar ou reciclar conhecimentos, habilidades ou atitudes relacionadas diretamente à execução de tarefas ou à sua otimização no trabalho. Observa-se que o treinamento aumenta o conhecimento do pessoal para melhor desempenhar a função dentro da organização e tem resultado instantâneo. Na empresa havia 3 supervisores de produção, todos promovido e formado na empresa, onde detinham cargo de motorista de empilhadeira, os três não adaptaram a nova política da empresa e foram dispensados, em seus lugares admitiu 1 que estava no mercado de trabalho e dois foram promovidos do chão-de-fábrica. Vale ressaltar que os supervisores liberados, foram julgados não aptos para exercer a função de liderança, mas atendendo o pedido da diretoria foram treinados, participaram de vários cursos oferecido pelo SENAC e SENAI.

Os líderes, dentro de uma empresa, correspondem ao principal elo que interfere diretamente no desempenho das atividades da mesma. São considerados como principais identificadores e agentes de comunicação de valores coletivos, e buscam assegurar recursos internos necessários para os funcionários, e são considerados, também, como ouvintes dos mesmos, pois são moderadores, defensores e motivadores de culturas organizacionais voltadas para o seu desempenho (ALMEIDA, 2012).

Etapa 3 (Ativação): Foi desenvolvido um mural com noticias da empresa e informação, poemas, noticias brasileira e mundial, ambiente etc, todas as informações havia data para ser removida.

Foi criado programa contra tabagismo, alcoolismo e dependente químico, diálogo de segurança e qualidade no trabalho.

Programa contra o tabagismo

Foi realizada palestra com médico, a empresa forneceu medicamento que auxilia no tratamento desde que o colaborador assinasse um termo de compromisso com a organização e família com a família, este termo foi assinado na casa do funcionário na presença da família.

O programa contra o tabagismo atingiu em 1 ano 100\% de eficácia, gerando 
um investimento de $\mathrm{R} \$ 7.523,66$.

O fumante pode ter até $12 \%$ menos da capacidade aeróbica, devido à maior concentração do monóxido de carbono no sangue. Durante o exercício, há prejuízo da respiração pela bronquite, e a musculatura trabalhada recebe suprimento sanguíneo com maior concentração de monóxido de carbono, com aumento da frequência cardíaca, para manter a demanda adequada de oxigênio na musculatura. O fumo também promove, durante o exercício, um custo energético adicional, provocado pelo maior trabalho dos músculos respiratórios. Com o abandono do tabagismo e a pratica regular da atividade física, a capacidade aeróbica pode voltar a valores normais (ARAÚJO, 2000; MONTEIRO, 1999).

Programa contra alcoolismo e dependente químico

Alcoolismo: foi necessário a internação de 3 colaboradores, 4 tiveram acompanhamento médico e 1 não aceitou ajuda, onde pediu demissão. Neste programa foi necessário investir $R \$ R \$ 18.456,87$.

O conceito do alcoolismo surgiu a partir do século XVIII, logo após o desenvolvimento da produção e comercialização do álcool destilado, consequente à revolução industrial. Durante este período destacaram-se dois autores: Benjamin Rush e Thomas Trotter. O primeiro, um psiquiatra americano, foi responsável pela frase "beber inicia um ato de liberdade caminha para o hábito e, finalmente, afunda na necessidade". E o segundo foi quem, pela primeira vez, se referiu ao alcoolismo como "doença". Outro autor de relevância foi Magnus Huss, que introduziu o conceito de "alcoolismo crônico", estado de intoxicação pelo álcool que se apresentava com sintomas físicos, psiquiátricos ou mistos (GLIOTTI, BESSA, 2004). Sabe-seque, no Brasil, o alcoolismo é o terceiro motivo para absenteísmo no trabalho, a causa mais frequente de aposentadorias precoces e acidentes no trabalho e a oitava causa para concessão de auxílio doença pela Previdência Social (VAISSMAN, 2004).

Dependente químico: os três casos aceitaram ser internados, foi necessário investir de $\mathrm{R} \$ 19.345,71$.

O uso de drogas existe cada vez mais entre pessoas incorporadas à vida produtiva, trazendo como consequências a diminuição da produtividade, alteração das relações na ordem laboral, interpessoal, familiar, social e da saúde (CARRILLO, MAURO, 2004). 
Na organização há CIPA, no entanto, não havia nenhuma festividade, jogos ou semana da CIPA. Foi realizada a semana da CIPA com dois dias de jogos, palestra e sorteios.

Etapa 4 (Avaliação): A empresa passou a dedicar a promoção da saúde e segurança do colaborador, promovendo educação, supervisão e planejamento das atividades.

O processo de implantação do endomarketing requer mudanças na cultura organizacional, tornando-a mais flexível e capaz de disseminar conhecimentos, gerar responsabilidades e delegar poder de decisão aos clientes internos (WEIRICH, et al, 2004). Esta mudança foi o item mais difícil de realizar, e após 1 ano de trabalho acredito não ter realizado plenamente.

Uma equipe de trabalho pode atingir alto nível de desempenho em termos de produtividade e qualidade, desde que seus membros sintam satisfação com suas tarefas e objetivos traçados, as relações interpessoais com os demais e a qualidade de vida no trabalho (CHIAVENATO, 1999). Fato observado após 4 meses de trabalho com o endomarketing.

A diretoria da organização relutou ao conhecer teoricamente o endomarketing, mas após visita a uma empresa que havia implantado o sistema, aceitou o desafio. Dez meses após o inicio do projeto sua percepção pode ser descrita da seguinte forma: o sistema de marketing interno tem contribuído com o desenvolvimento da empresa e, principalmente, das pessoas; os instrumentos já implantados precisam ser aprimorados; a coordenação do processo deve ser uma responsabilidade da área de recursos humanos; percebe um comportamento com a melhoria do sistema na empresa; identifica a necessidade de aperfeiçoar o sistema como um todo, repensando a definição dos seus objetivos e sugerindo criar novos instrumentos que

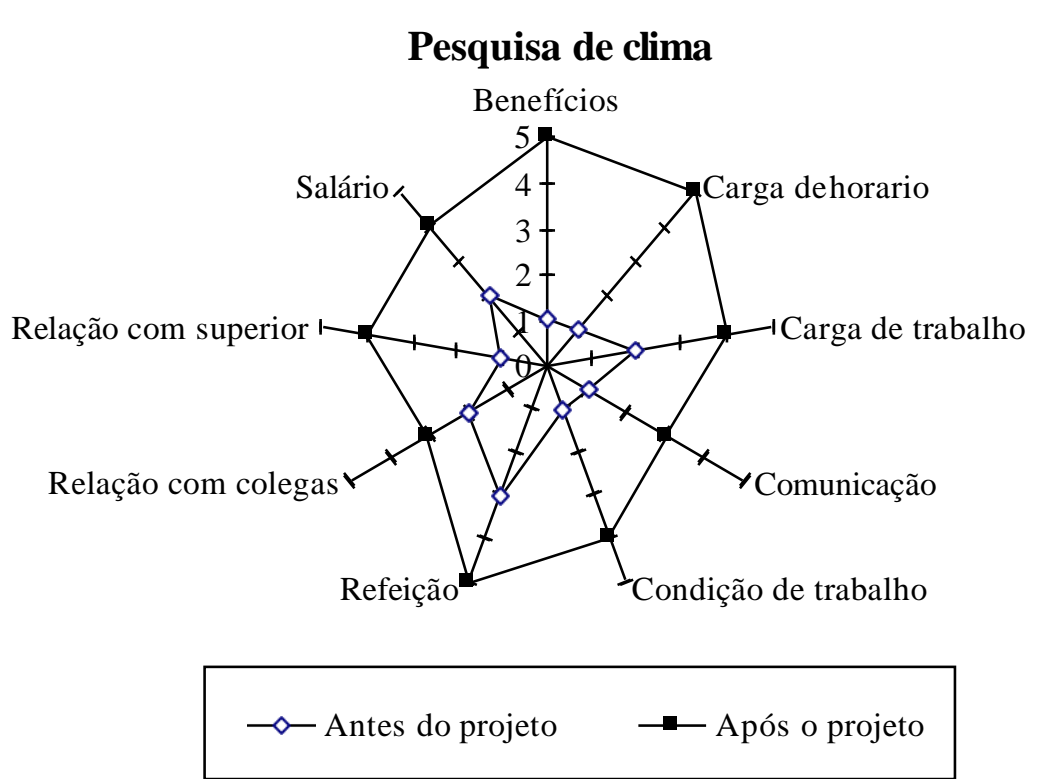


abordam aspectos mais emocionais, percepção também relatada por Behnenberger e Pinheiro (2002).

Gráfico 1: Comparação da satisfação dos colaboradores antes e após a implantação do endomarketing.

A empresa abriu a porta para família visitar, o dia começava com uma palestra falando da história da empresa e explicando o valor dos colaboradores, após a palestra servia café da manhã e seguia a área da empresa, terminado a visita cada visitante recebia uma camiseta adulta ou infantil, mochila confeccionada de material reciclável, caneta e régua.

Foi fornecido 3 bolsas de estudo para cursar administração e contabilidade, ajuda de custo de transporte. Houve palestra explicando o beneficio de estudar e onde poder realizá-los. Em julho de 2012, 35 colaboradores matricularam no supletivo, 10 em ensino normal e 6 em ensino superior.

Para sanar o esgotamento físico mudou o layout do processo, criou-se planejamento de rotina para todos, descrição de cargo e salário e instalou 3 talhas para levantar peso, adquiriu 2 empilhadeira. A descrição de cargos e salário propiciou o ajuste de salário de $8 \%$.

Após 3 meses, 6 meses, 9 meses e 12 meses da implantação do projeto, a porcentagem de colaboradores que indicaria a empresa para amigo e parente foi de $26,47 \%$ / 48,03\% / 79,41 e 98,04\% respectivamente, fato que deixou a diretoria satisfeita.

Baniu o termo empregado e funcionário da organização, adotou apenas colaborador.

Todo funcionário recebia o feedback trimestralmente.

Observa-se no gráfico 1 que a pesquisa de satisfação realizada 12 meses após o inicio dos trabalhos mostrou enorme aumento na satisfação dos colaboradores.

Uma ferramenta que poderia ter colaborado com o programa é o 5S, pois segundo Pasquini (2012) que implantou o 75 proporcionou ganho na mudança de comportamento dos colaboradores, disciplina, economia, higiene, limpeza e organização tornaram-se praticas comuns, melhorou muito o gerenciamento de rotina dos supervisores, gerentes e em menor grau do chão de fabrica.

Em 2012 ocorreu 3 acidentes com afastamento e 4 sem afastamento, uma 
diferença significativa com os anos anteriores.

\section{CONCLUSÃO}

No mercado de trabalho há profissionais em cargo de liderança, cujos conhecimentos, habilidades e principalmente valores são questionáveis. Não há como criar um líder, imbuir no ser humano os valores necessários, pode sim desenvolver ou moldar estes valores em quem nasceu para ser tal. $O$ endomarketing mudou a "cara" da empresa, aumentou a produção em $17 \%$ sem horas adicionais. Atingiu rapidamente 0 marketing externo, se tornando benchmarking na região de Americana SP, pois os colaboradores se tornaram multiplicadores da boa imagem.

O programa obteve sucesso devido à ótima comunicação que ocorreu na organização, isto foi 0 fator determinante seguida do querer que funcione proveniente dos diretores, na qual não mediram esforços.

$O$ alicerce do sistema de qualidade é o conhecimento de cada processo. Uma análise minuciosa utilizando as ferramentas adequadas é útil para diagnosticar as causas que atuam sobre os processos. As ferramentas definem o que foi feito certo, o que foi feito errado e o que precisa ser reparado ou não, tais ferramentas permite ter um conjunto de indicadores de desempenho e permite a medição do desempenho articulada nos micro e macroprocessos. As ferramentas de qualidade são úteis para gerenciar uma empresa e são simples de usar, mas não se deve enganar por essa simplicidade (PASQUINI, RIBEIRO, 2010).

\section{REFERENCIAS BIBLIOGRAFICAS}

ALMEIDA, M. M. A escassez de líderes no mercado de trabalho: o papel do professor universitário na formação deste profissional pode colaborar para a mudança do cenário atual. Gestão \& Sociedade. v. 1, n. 1, 2012. Disponível em: http://uniabeu.tempsite.ws/publica/index.php/gs/article/view/410/pdf 195. Acessado em 07/12/2013.

ANDRADE, F. F. de. O método de melhorias PDCA. 2003. Dissertação (Mestrado em Engenharia de Construção Civil e Urbana) - Escola Politécnica da Universidade de São Paulo, São Paulo, 2003. Disponível em:

http://www.teses.usp.br/teses/disponiveis/3/3146/tde-04092003-150859/pt-br.php. Acesso em: 25/12/2013.

ARAÚJO, C. G. S. Teste de esforço e prescrição de exercício. 5ed. Rio de Janeiro: 
Revinter: 2000.

Beking SF. Endomarketing: como praticá-lo com sucesso. São Paulo: Pretenci Hall; 2004. 186p.

BEKIN, S. F.. Conversando sobre Endomarketing. São Paulo: Editora Makron

Books, 1995. BENITE, A. G.. Sistemas de gestão da segurança e saúde no trabalho: conceitos e diretrizes para implementação da Norma OHSAS 18001 e Guia ILO OSH Da OIT. São Paulo: O Nome da Rosa, 2004.

BOHNENBERGER, M. C.; PINHEIRO, I. A. Endomarketing - uma ferramenta a ser explorada para obter vantagens competitivas. READ, v. 8, n. 4, 2002.

BRUM, A. M. Endomarketing como Estratégia de Gestão: encante seu cliente Interno. Porto Alegre: L\&PM, 1998.

BRUM, M. Um olhar sobre o marketing interno. Porto Alegre: L\&PM, 2000.

CARRILLO, P. L. L.; MAURO, M. Y. C. O trabalho como fator de risco ou fator de proteção para o consumo de álcool e outras drogas. Read de Revista Científicas de América y el Caribe. 13(2): 217-25, 2004.

CARVALHO, Luiz Carlos. Endomarketing em nova perspectiva. [2010].

Disponível em:

http://casesdesucesso.wordpress.com/2010/04/06/endomarketing-em-novaerspectiva Acesso em: 19 dez. 2013.

Cerqueira W. Endomarketing: educação e cultura para a qualidade. Rio de Janeiro: Qualitymark; 2002. 161p.

CHIAVENATO, Idalberto. O novo papel dos recursos humanos nas organizações.

3. ed. Rio de Janeiro: Elsevier, 2008.

CHIAVENATO, I. Administração nos Novos Tempos. 2. ed. Rio de Janeiro: Campus, 1999.

CHIAVENATO, I. Recursos Humanos. São Paulo: Atlas, 1998.

COSTA, M. A. F..; COSTA, M. F. B.. Segurança e saúde no trabalho: cidadania, competitividade e produtividade. Rio de Janeiro: Qualitymark, 2004.

DIAS, José Geraldo Gaurink. Endomarketing: um instrumento estratégico na busca da melhoria da competitividade empresarial. São Paulo: Livro Pronto, 2008. GIGLIOTTI, A.; BESSA, M. A. Síndrome de Dependência do Álcool: critérios diagnósticos. Rev. Bras. Psiquiatr., São Paulo, 2012 Disponível em:

http://www.scielo.br/scielo.php?script=sci arttext\&pid=S1516- 
44462004000500004\&Ing=en\&nrm=iso Acessado em: 04/11/2014.

GIL, A. C. Métodos e Técnicas de Pesquisa Social. São Paulo; Atlas 2007. GONZÁLEZ, R. M. Endomarketing - informação e comunicação total - por Viviane Pacheco. Revista Surftrade, 2000.

KOTLER, P. Princípios de marketing. Rio de Janeiro: Prentice-Hall do Brasil, 1993. 478p. MARINS, C. S.; SOUZA, O. D.; SANTOS, R. F.; GAMA, A. M.; AZEVEDO FILHO, E. T.;

Endomarketing: Uma ferramenta estratégica para o aumento da produtividade. XXX Encontro Nacional de Engenharia de Produção, 2010. Disponível em: http://www.abepro.org.br/biblioteca/enegep2010 TN STO 113739 15201.pdf. Acessado em: 02/12/2012.

MARRAS, J. P.. Administração de recursos humanos. São Paulo: Futura, 2002. MEDEIROS, L. F. R.; MACÊDO, K. B. Profissão: catador de material reciclável, entre o viver e o sobreviver. G\&DR - v. 3, n. 2, p. 72-94, mai-ago /2007. Disponível em: http://www.rbgdr.net/revista/index.php/rbgdr/article/view/8/4. Acessado em: 17/12/2012.

MONTEIRO, W. D. Manual para avaliação e prescrição de condicionamento físico. $2^{\mathrm{a}}$ ed. Rio de Janeiro: Sprint; 1999.

OLIVEIRA, S. T. Ferramentas para o aprimoramento da qualidade. 2. ed.. São Paulo: Pioneira, 1996.

PASQUINI, N. C.; RIBEIRO, A. M. da ROCHA. Avaliação do uso de ferramentas da qualidade em empresas do setor têxtil instalada na Região do Pólo Têxtil (RPT). Revista Eletrônica de Administração (Online), v. 09, n.1, edição 16, jan-jun 2010. Disponível em: http://periodicos.unifacef.com.br/index.php/rea/article/view/477. Acessado em: 21/11/2013.

PASQUINI, N. C. Implantação do programa $7 S$ em uma empresa metalúrgica, benefícios e dificuldades. Revista Qualidade Emergente, 2012, v.3, n. 1, 3-19, 2012. Disponível em: http://ojs.c3sl.ufpr.br/ojs2/index.php/qualidade/article/view/27547. Acessado em: 23/10/2013. PUENTE-PALACIOS, K. ; FREITAS, I. A. Clima organizacional: uma análise de sua definição e de seus componentes. o\&s - v.13 n.38 - Julho/Setembro - 2006

RICHERS, R. Marketing: uma visão brasileira. São Paulo: Negócio, 2000.

VANTI, N. Ambiente de qualidade em uma biblioteca universitária: aplicação do $5 \mathrm{~S}$ e 
de um estilo participativo de administração. Ci. Inf., set./dez. 1999, vol.28, no.3, p.333-339. ISSN 0100-1965.

VAISSMAN, M., Alcoolismo no trabalho, Editora Fiocruz e Garamond, 2004.

WEIRICH, C. F.; MUNARI, D. B.; BEZERRA, A. L. Q. Endomarketing: ensaio sobre possibilidades de inovação na gestão em enfermagem. Rev Bras Enferm, Brasília (DF) 2004 nov/dez;57(6):754-7. 